\title{
AUTOMATIC DETECTION OF PLANTED TREES AND THEIR HEIGHTS USING PHOTOGRAMMETRIC RPA POINT CLOUDS
}

\section{Detecção automática de árvores e alturas em plantios florestais por meio de nuvens de pontos fotogramétricas de RPA}

Kênia Samara Mourão Santos ${ }^{1}$ - ORCID: 0000-0002-0233-6910

Christel Lingnau² - ORCID: 0000-0002-9469-8600

Daniel Rodrigues dos Santos ${ }^{3}$ - ORCID: 0000-0001-7977-7426

\author{
${ }^{1}$ Universidade Federal do Paraná, Programa de Pós-graduação em Engenharia Florestal, Curitiba- PR, Brasil. \\ E-mail: keniasmsantos@gmail.com \\ ${ }^{2}$ Universidade Federal do Paraná, Departamento de Ciências Florestais, Curitiba- PR, Brasil. \\ E-mail: lingnau@ufpr.br \\ ${ }^{3}$ Universidade Federal do Paraná, Departamento de Geomática, Curitiba- PR, Brasil. \\ E-mail: danielsantosufpr@gmail.com
}

Received in $26^{\text {th }}$ April 2020.

Accepted in $20^{\text {th }}$ August 2021.

\section{Abstract:}

This work aims to analyze the potential of the Photogrammetric Point Cloud (PPC) obtained from Remote Piloted Aircraft (RPA) optical images for detecting and obtaining tree heights in a loblolly pine plantation using a global maximum filter. The enhanced algorithm used in this study is then named STD (Single Tree Detection). Field surveys were conducted to count all the trees in the field (Forest Census) and measure the trees' height with a vertex hypsometer. The results were faced to PCC outcomes. The detection rate ( $r$ ) was equal to the precision rate (p), indicating that the algorithm reaches a high tree detection performance. In summary, the STD algorithm segmented 2,192 trees, representing $89 \%$ of trees recorded in the forest census. The retrieved tree height reached, on average, a height of $17.05 \mathrm{~m}$, whereas slightly higher by the traditional forest inventory $(17.42 \mathrm{~m})$. The root-mean-square error (RMSE) and Bias were $47 \mathrm{~cm}(2.8 \%)$ and $-37 \mathrm{~cm}(-2.2 \%)$, respectively. The Dunnett test showed that the tree height did not significantly differ between the results obtained by traditional forest inventory from those generated by the STD. It confirms the potential use of PPC for forest inventory procedures.

Keywords: Forest census; Loblolly pine; Global maximum filter; tree height; RPA

How to cite this article: SANTOS, K.S.M.; LINGNAU, C.; SANTOS, D.R. Automatic detection of planted trees and their heights using photogrammetric RPA point clouds. Bulletin of Geodetic Sciences. 27(3): e2021025, 2021. 


\section{Introduction}

Forest measurement techniques are necessary for wood stock quantification (Nicoletti et al. 2020). Measurement of forest productivity is closely related to the total height (Leite and Andrade 2003) and the number of trees in the stand. However, measuring tree height in the stand can lead to time-consuming, costly procedures and errors, as it requires knowledge of the horizontal distance from the operator to the tree and good visibility of the base and top (Mendonça et al. 2011). Similarly, the counting of trees in forest plantations is also a high-cost activity. Currently, it is usually performed by field surveys: visual counting through orthoimage photointerpretation of Remotely Piloted Aircraft (RPA) aerial images or by 3D point cloud, derived from the Light Detection and Ranging (LiDAR) system.

In the context of 3D point clouds, progress in digital photogrammetry has made it possible to obtain this information from optical images (Dandois and Ellis 2013) with great applicability in the forest environment (Dandois and Ellis 2013; Leslar 2015; Tang and Shao 2015; Tompalski et al. 2019). The development of methods for the automatic detection of trees with accuracy from Photogrammetric Point Cloud (PPC) of optical images has the potential to reduce forest inventory costs for tree accounting, either in the field or through visual interpretation of orthophotos. According to Dandois and Ellis (2013) these clouds have 3D representation characteristics similar to those obtained with 3D point clouds from LiDAR systems when applied in forest areas (Dandois and Ellis 2013). However, in contrast to LiDAR, PPC is limited to the top canopy surface with ground points located only when the ground can be observed on the image, such as in canopy gaps or exposed ground (Tompalski et al. 2019). Studies show the applicability of PCC derived from optical images in forests, make it possible to obtain relevant information, such as average tree height in urban areas (Zarco-Tejada et al. 2014), biomass (Skowronski et al. 2014 ), volume (Kameyama et al. 2020), height (Krause et al. 2019; Kameyama et al. 2020) and the forest census (Wallace et al. 2014). However, there are few studies (Oliveira et al. 2021) in the literature that address the use of PPC from RPA optical images for tree detection and height inhomogeneous planted stands.

Most methods of automatic tree detection from PPC consist of converting the cloud into raster data (matrix format) and then using the local maximum filter. But it is known that this type of conversion leads to loss of important three-dimensional information in detecting individual trees and obtaining their height (Li et al. 2012). A study by Li et al. (2012), for example, showed the potential of global maximum filters for detecting LiDAR 3D point cloud trees, which presented higher assertiveness than local maximum filters (Wallace et al. 2014).

Given the above, the goal of this study was to analyze the potential of PPC to be used in the detection, counting, and height retrievals of a loblolly pine plantation using RPA images and global maximum algorithm.

\section{Materials and Methods}

\subsection{Study area and data acquisition}

The study was conducted on a 4.5-hectare Pinus taeda stand (loblolly pine plantation), located in the municipality of São Mateus do Sul, Paraná State, Brazil (W 50 o 35 '27.070” and S 25 55’ 36.291” DATUM SIRGAS 2000), on farms belonging to the FComp Ltda Company. The specific forest stand selected for this study has 11-yearold, $2.5 \mathrm{~m} \times 2.5 \mathrm{~m}$ spacing with submitted mixed thinning (selective and systematic harvesting in the 5 th row). The climate of the study area was classified as Temperate Oceanic Climate (Cfb type), which is mesothermic, humid subtropical, with mild summers, undefined dry seasons, and the occurrence of severe frosts; with an average 
annual temperature of $16^{\circ} \mathrm{C}$, and annual precipitation ranging from 1300 to $2400 \mathrm{~mm}$ (Nicoletti et al. 2020). This kind of management is more common in areas of planted forest destined for the production of sawmill wood. The division of the field (Figure 1) into blocks was established in the systematic thinning lines. Tree detection and forest census were performed on twelve blocks.
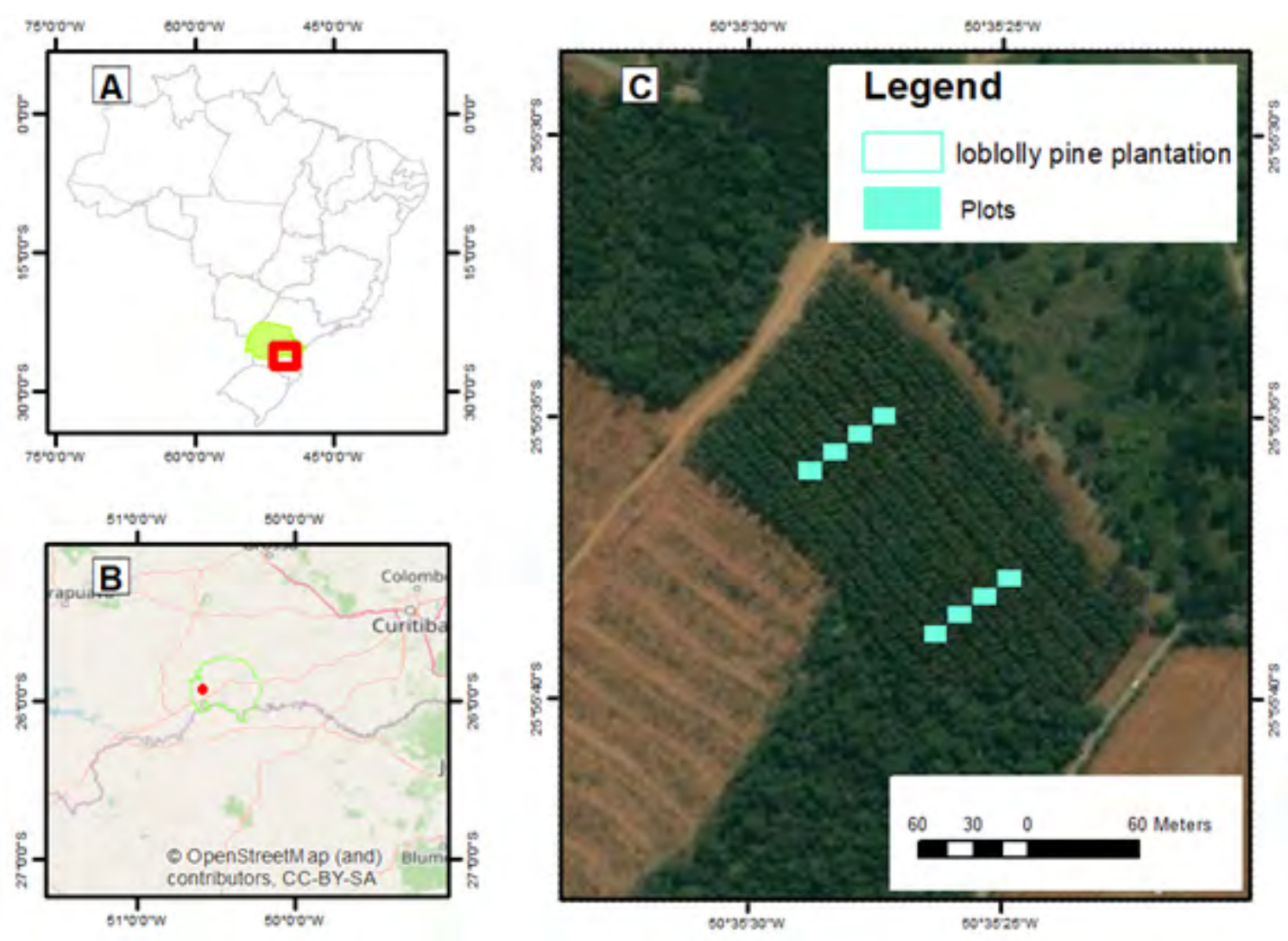

Source: The Author.

Figure 1: A) Paraná state location; B) São Mateus do Sul municipality location; C) Loblolly pine plantation; D) Perspective RGB image acquired from DJI Phantom 4 Pro of loblolly pine plantation used to implement the automatic tree detection algorithm.

To validate the results obtained through the PCC, field surveys were made counting all the trees in the field (Forest Census) and measuring the height of the trees with a vertex hypsometer model VL4 vertex laser haglof. The measurements were made in 8 rectangular plots of $12.5 \mathrm{~m} \times 17.5 \mathrm{~m}$ distributed in the study area. The total area of the sample plot was $218.75 \mathrm{~m}^{2}$ and the plots cover $0.44 \%$ of the total study area.

\subsection{Survey and Photogrammetric Point Cloud preprocessing}

The flight was performed with the DJI Phantom 4 Pro Drone quadcopter. The RGB camera with a focal length of $24 \mathrm{~mm}, 20$ megapixels and a GPS was integrated into the quadcopter. The camera sensor has dimensions of $8 \mathrm{x}$ $11 \mathrm{~mm}$. The aerial photographs were obtained by two flights: $100 \mathrm{~m}$ and $120 \mathrm{~m}$, with the longitudinal overlap of $80 \%$ and lateral overlap of $70 \%$. The survey of aerial photographs was performed in cross flight, thus obtaining a greater coverage of the photography in the object space and, consequently, to their level of detail. The flights were performed between 10:00 and 14:00 hours on June 23rd, 2017. 
The PPC (Figure 2) was automatically generated from images using the computer vision software Agisoft Photoscan version1.2.4. The software generates first the sparse point cloud, by aligning photos via reference pair preselection. The next step is to build Mesh and finally build the dense point cloud. The PPC produced consists of a set of 3D points in an arbitrary coordinate system, but with internally consistent geometry, with RGB information extracted from each point of the input photos (Dandois and Ellis 2013).

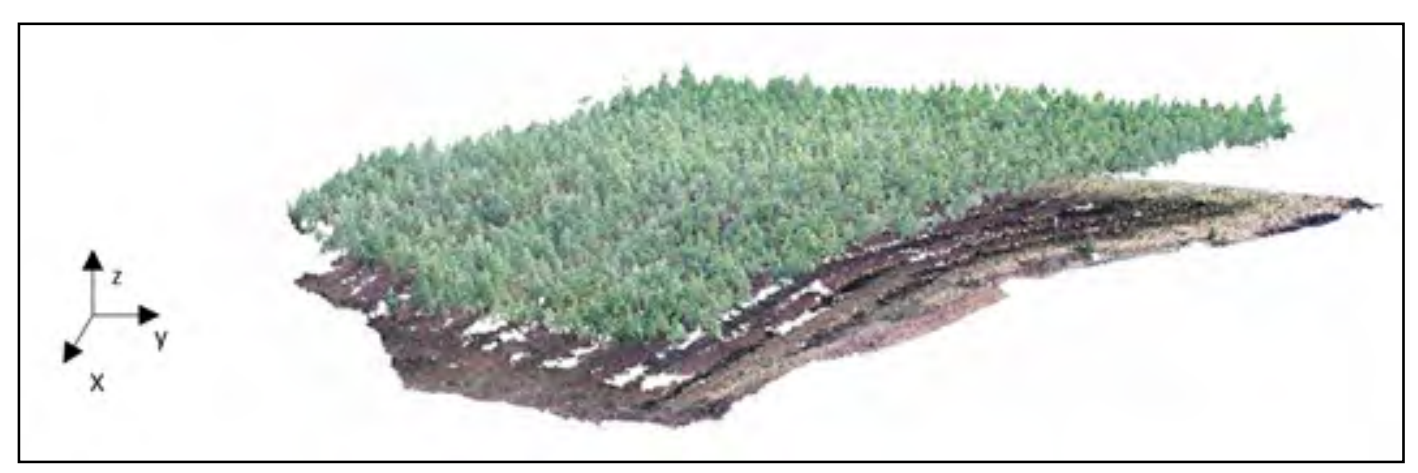

Source: The Author

Figure 2: Photogrammetric point cloud 3D visualization for the study area.

The global maximum algorithm was applied to the treated PPC. The methodological flowchart (Figure 3) presents the steps for obtaining the treated PPC.

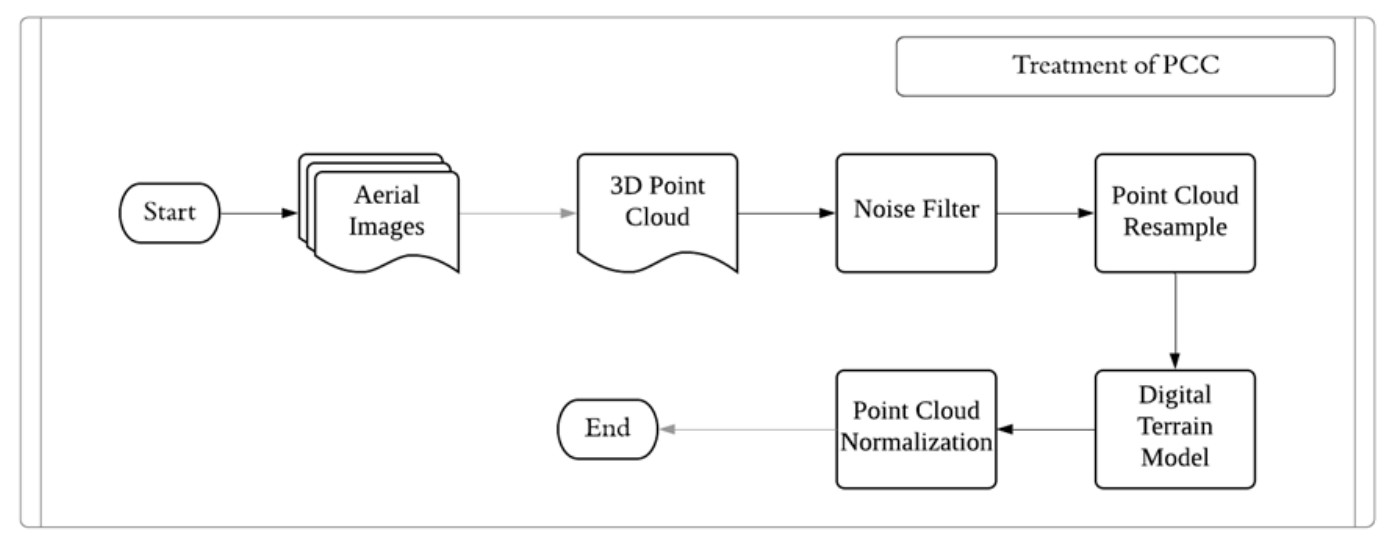

Source: The Author

Figure 3: Major steps of the Photogrammetric Point Cloud data processing.

PPC is subject to high noise or outliers. To correct these errors, the Statistical Outlier Removal (SOR) algorithm (Rusu et al. 2008), was implemented by a plugin in CloudCompare 2.9 software. The S.O.R plugin is a simple interface to some methods of the PCL library. The SOR works through two phases of interaction with the entry. In the first interaction, it calculates the average distance between each point and its k closest neighbors. The $k$ value is configured by the user. Then, the mean and standard deviation of all these distances are computed to determine the limit distance between the points. In the second interaction, the points are classified as inlier or outlier according to the calculated limit: if the point is above the limit, it will be considered an outlier, and if it is below, an inlier (PCL Library). 


$$
\text { MaxDist }=\frac{\sum x i}{n} \pm a \sqrt{\frac{\sum_{i=1}^{n}\left(X_{i}-\bar{X}\right)^{2}}{n-1}}
$$

where: MaxDist is the boundary distance between points, $X i$ is the individual point in PPC, $\bar{X}$ is the average of points, $n$ is the point quantity, $X_{i}$ is the average distance and $\alpha$ is the multiplier constant of standard deviation.

To reduce computational resources, data processing, and redundancy, high-density point sampling processes were adopted. However, this sampling process should be carefully considered, as it must be able to represent the phenomenon as a whole without loss of information (Miranda et al. 2018). In the present study, only $1 \%$ of the total points in the 3D point cloud were used, which were selected by simple random resampling. The $1 \%$ value was adopted following tests with the percentages: $1 \%, 5 \%$, and $10 \%$, and verified with no change in the final results, except on processing time. The Digital Terrain Model (DTM) is obtained from spatial data that represent the surface to be modeled (Miranda et al. 2018). The PPC can act as a reference database for generating a model of the surface distribution, however, it can present points that do not represent the layer to be modeled. Therefore, these clouds must go through a filtering process to extract only the points of interest. For this, the PPC obtained was submitted to the Cloth Simulation Filtering (CSF) algorithm (Zhang et al., 2016), originally developed for filtering points corresponding to the aerial laser data soil and implemented in the free software CloudCompare 2.9.

The CSF extracts points referring to the soil through modeling of the "Cloth modeling" mesh, where a mesh is simulated on the reverse cloud, resulting in a basis for the classification of points into ground and non-ground. In some cases, as in Haala et al. (2010), the securing of forest ground points by passive sensors is quite limited, or even impossible, due to the canopy. However, due to the mixed thinning present in this forest, it was possible to obtain ground information with a passive sensor, because of the canopy's openness after cutting some trees.

The variation in the ground's relief must be removed to obtain absolute heights of the trees. Thus, it is necessary to normalize the PPC concerning the field DTM. In this process, the points belonging to the ground, obtained by the CSF filtering, go through the process of Triangular Irregular Network (TIN), thus generating a continuous surface of the ground. Non-ground PPC was interpolated and subtracted from DTM, resulting in cloud normalization (Wang et al. 2008) (Equation 2).

$$
n D S M=D S M-D T M
$$

where: $n D M S$ is the normalized Digital Surface Model, DSM is the Digital Surface Model and DTM is the Digital Terrain Model.

The tree detection occurs from the normalized cloud, where points belonging only to the portion of the forest canopy were selected and extracted. The algorithm produced in this work was developed to work only in the forest canopy portion, for improved performance. The file resulting from the processing of the algorithm in the PPC of the field study consists of $E, N$, h coordinates, which match the map projection (UTM - SIRGAS2000). The algorithm was applied following the flowchart steps in Figure 4. 


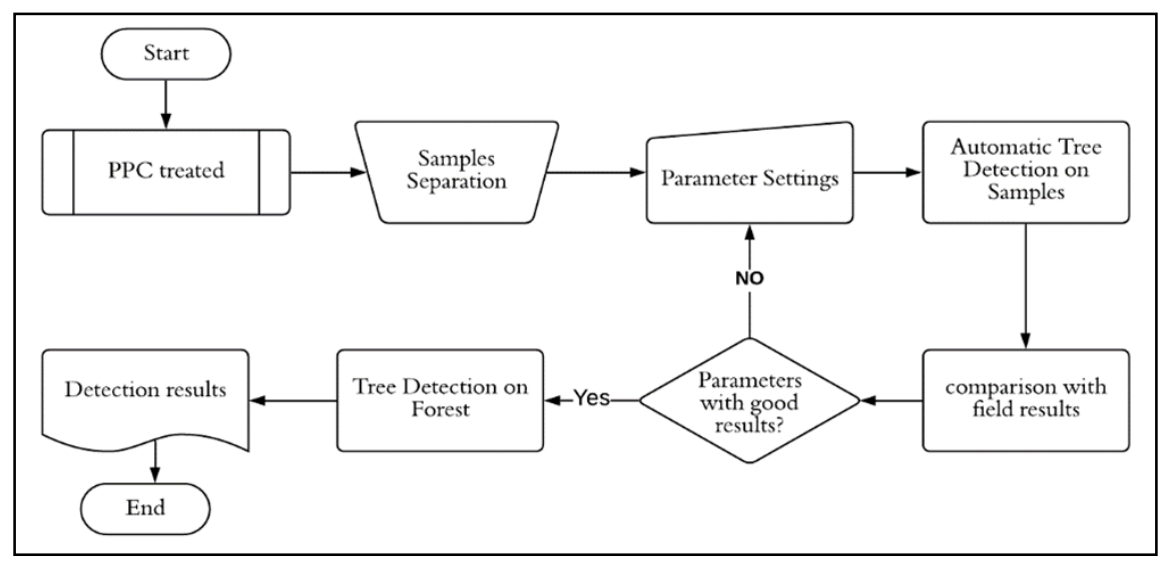

Source: The Author.

Figure 4: Algorithm flowchart to tree detection using RPAS optical images.

The blocks 03 and 04 (Figure 1D) were used as training samples to adjust the parameters established for the algorithm. From these blocks, the algorithm was adjusted according to the canopy characteristics of the forest tested, such as canopy spacing and height.

\subsection{Single Tree Detection Algorithm}

The algorithm for automatic tree detection (STD - Single Tree Detection) is performed by the global maximum method applied directly on the PPC treated (Santos 2018). The global maximum method has already been used by Li et al. (2012) for tree detection in LiDAR point clouds, but without the purpose of obtaining tree height. In this method, the highest point in the normalized point cloud is considered to belong to the first tree and all other points are evaluated against a set of criteria to determine if they belong to this initial tree (Li et al. 2012; Wallace et al. 2014). The most important criterion used to determine if a point in a given 3D point cloud belongs to a tree ' $n$ ' (befitting the global maximum of that cloud) is by applying a search radius. The radius is projected on the orthogonal plane (2D) points existing within this radius that meet the established parameters are classified as belonging to the tree ' $n$ '. Once the ' $n$ ' tree has been segmented, it is then separated from the 3D point cloud and the filter passes again, obtaining the ' $n+1$ ' tree and so on until the cloud is completely classified. The flowchart (Figure 5 ) illustrates how the algorithm works in the point cloud preprocessed.

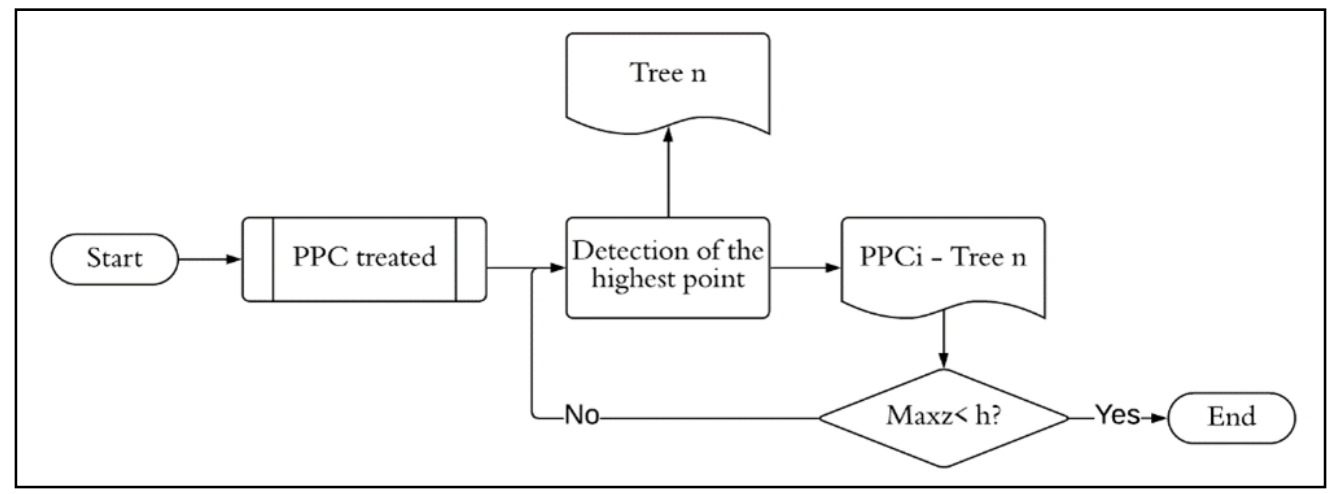

Source: The Author adapted from Li et al. 2012.

Figure 5: STD Algorithm flowchart to tree detection obtained from RPAS optical images. 
The MaxZ parameter was set to $\mathrm{H}_{\text {canopy }}+1$. This parameter represents the smallest possible height to be included in the automatic tree detection. The proposed algorithm for automatic tree detection was written in the Python programming language, using the Arcpy package (ESRI). Operation is based on the following pseudocode:

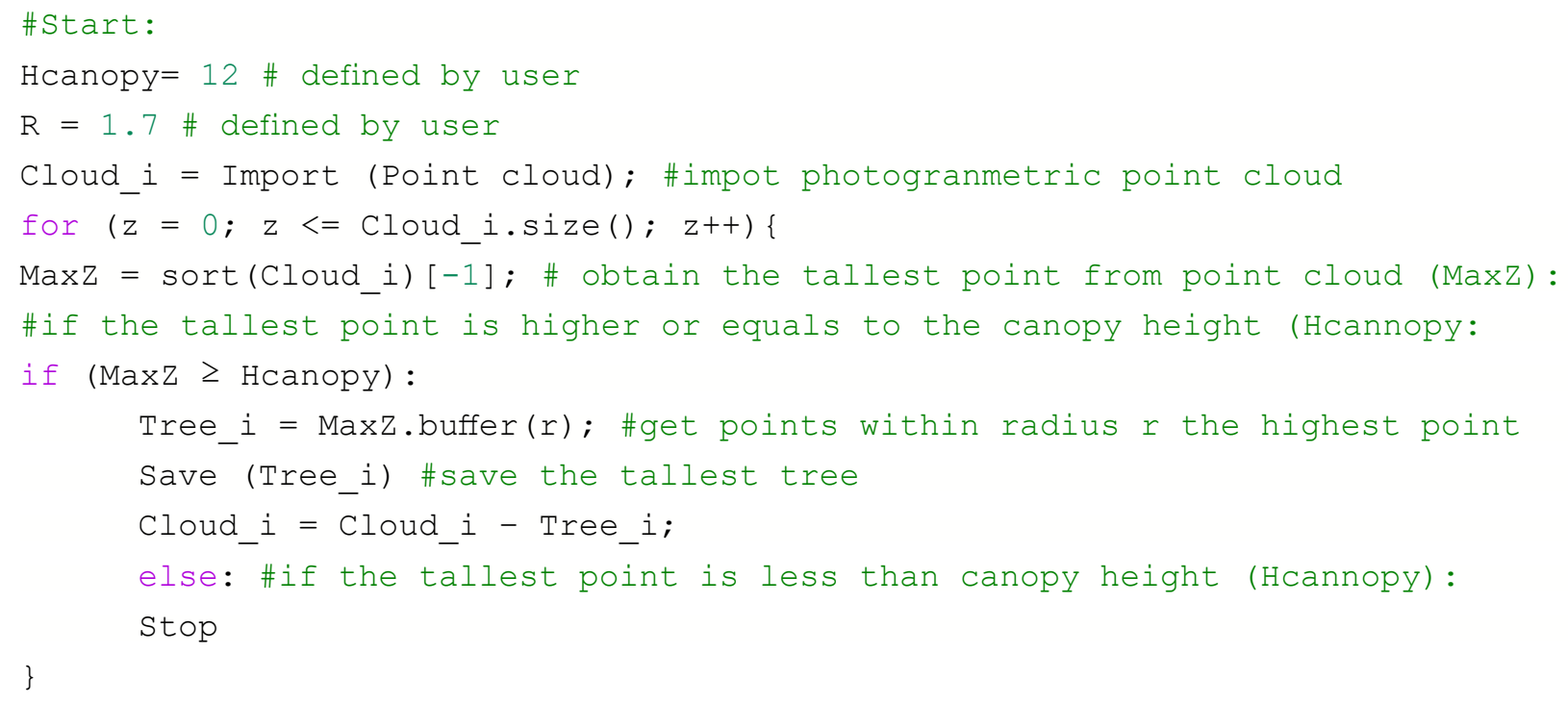

The " $R$ " in pseudocode indicates the radius and $H_{\text {canopy }}$ is the height of the canopy base (Figure 6). Both parameters should be defined according to the characteristics and spacing of the forest stand.

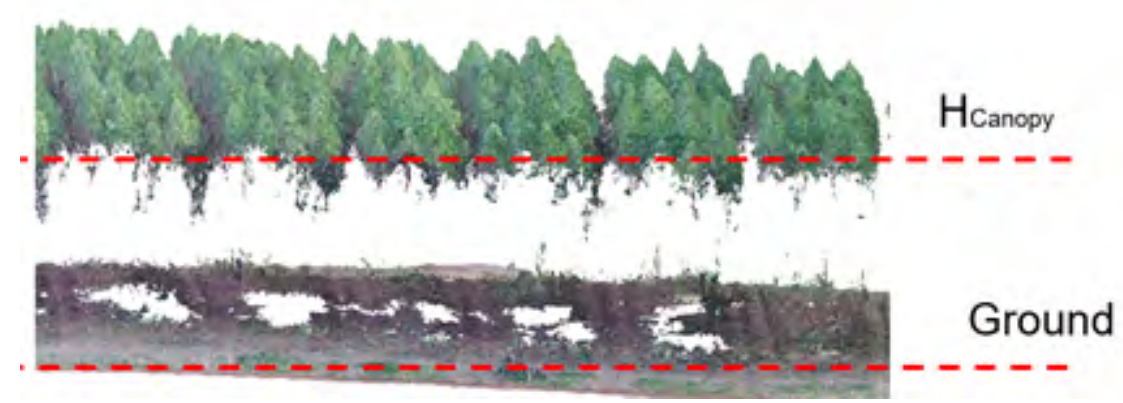

Source: The Author.

Figure 6: Representation of obtaining the $\mathrm{H}_{\text {canopy }}$ parameter in the PPC of an adult forest planted.

The automatic tree detection algorithm ranks neatly from the highest to the lowest tree until the cloud in the process has no points to classify ( $M a x Z n<\mathrm{H}_{\text {canopy }}$ ). As the PPC used as input to the STD is normalized, the $Z$ value of the detected points was assumed to be the total height of the detected trees, and these values were compared with those collected in the field.

\subsection{Data analysis strategy}

In addition to tree quantity collected by the census, the tree counting was also performed via photointerpretation. The results of both methodologies were compared to those obtained by the STD algorithm in the 3D point cloud. Tree heights obtained by field survey were compared to the heights obtained by the algorithm 
applied in the 3D point cloud of RPAS optical images.

The evaluation of detection and counting accuracy was analyzed at the block level ( 12 blocks) and was based on the analysis of commission and omission errors generated by the algorithm compared to the trees accounted for in the field (reference) and by the photointerpretation. Recall rates ( $r$ ) (Equation 3), precision rates (p) (Equation 4), and F-score (Equation 5) were calculated (Goutte and Gaussier 2005; Sokolova et al. 2006).

$$
\begin{gathered}
r=\frac{T P}{T P+F N} \\
p=\frac{T P}{T P+F P} \\
F-\text { Score }=2 \frac{r^{*} p}{r+p}
\end{gathered}
$$

where: $T P$ is the True Positives (trees correctly detected by the algorithm or true positives), $F N$ is the False Negative (when tree exists but do not get detected by algorithm or omission error), FP is the False Positive (when the tree does not exist, however, the point was detected as a tree or commission error), $r$ is the detection rate, $p$ is the precision rates and the F-Score.

The $r$ (recall) (Equation 3) indicates the tree detection rate, i.e. it is an indicator of correct detection by the algorithm, where $p$ indicates the precision of the algorithm and the F-Score is the overall accuracy, taking into account commission errors and omission, where the values of $r, p$ and F-score range from 0 to 1 , so that 1 is the maximum value given for perfect result (Li et al. 2012).

The mean values of tree height present in the eight plots were determined by hypsometers and STD algorithm, which were compared to test the hypothesis that the means, variances, and covariance of the variables do not differ between the two methods. First, the Shapiro Wilk normality test was performed. After this step, Bartlett's homogeneity test was applied, and finally, Dunnett's comparison test (Dunnett and Tamhane, 1995) was performed (Equation 6).

$$
\text { d.m.s }=d \sqrt{\frac{2 * Q M R}{r}}
$$

where: $d . m . s$ is the significant minimum difference, $d$ is the in the value given in the table at the pre-established significance level, $Q M R$ is the mean square of the residue of the analysis of variance and $r$ is the number of treated groups. The root-mean-square error (RMSE) and Bias were obtained from Equation 7 and Equation 8, respectively.

$$
\begin{aligned}
R M S E & =\sqrt{\sum_{i=1}^{n} \frac{\left(\hat{y}_{i}-y_{i}\right)^{2}}{n}} \\
\text { Bias } & =\sqrt{\sum_{i=1}^{n} \frac{\left(\hat{y}_{i}-y_{i}\right)}{n}}
\end{aligned}
$$

where: $R M S E$ is the root-mean-square error, Bias is the bias value, $\hat{y} i$ is the predicted, value, $y_{i}$ is the observed value and $n$ is the number of observations. Pearson correlation coefficient $(r)$ and coefficient of determination $\left(R^{2}\right)$ were also calculated.

\section{Results and Discussion}

Overflight with RPA resulted in 214 images with $2 \mathrm{~cm}$ spatial resolution. From these images, a PPC was obtained, with a total of 32,085,461 points, representing the canopy and the soil portion. Although the RPAS camera 
is a passive sensor, and due to the characteristics of the studied forest (recently thinned), it was possible to obtain the ground from inside the planting and thus perform the cloud normalization process (Figure 7).

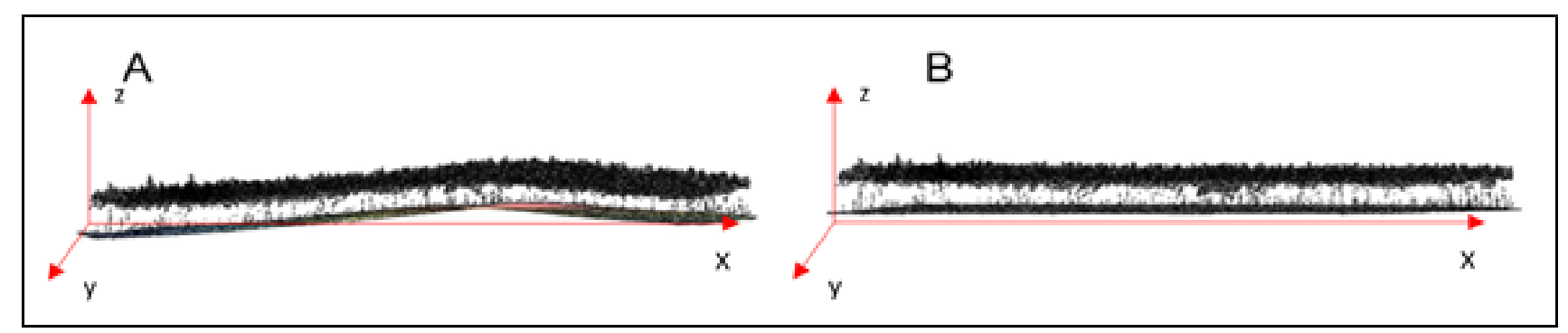

Source: The Author.

Figure 7: Photogrammetric Point Cloud normalization. A) PPC before normalization; B) PPC after normalization.

\subsection{Tree detection}

The BL03 and BL04 blocks (Figure 8A) used to adjust the algorithm parameters allowed the $\mathrm{H}_{\text {canopy }}=12 \mathrm{~m}$ and $r=1.7 \mathrm{~m}$ values. The radius defined for the algorithm adjustment was based on the distance between the crowns of the canopy, obtained by empirical approach by randomly measuring some trees in the orthophoto. Figures $8 \mathrm{~B} ; 8 \mathrm{C}$ and $8 \mathrm{D}$ indicate the results of classification on these specific training blocks.

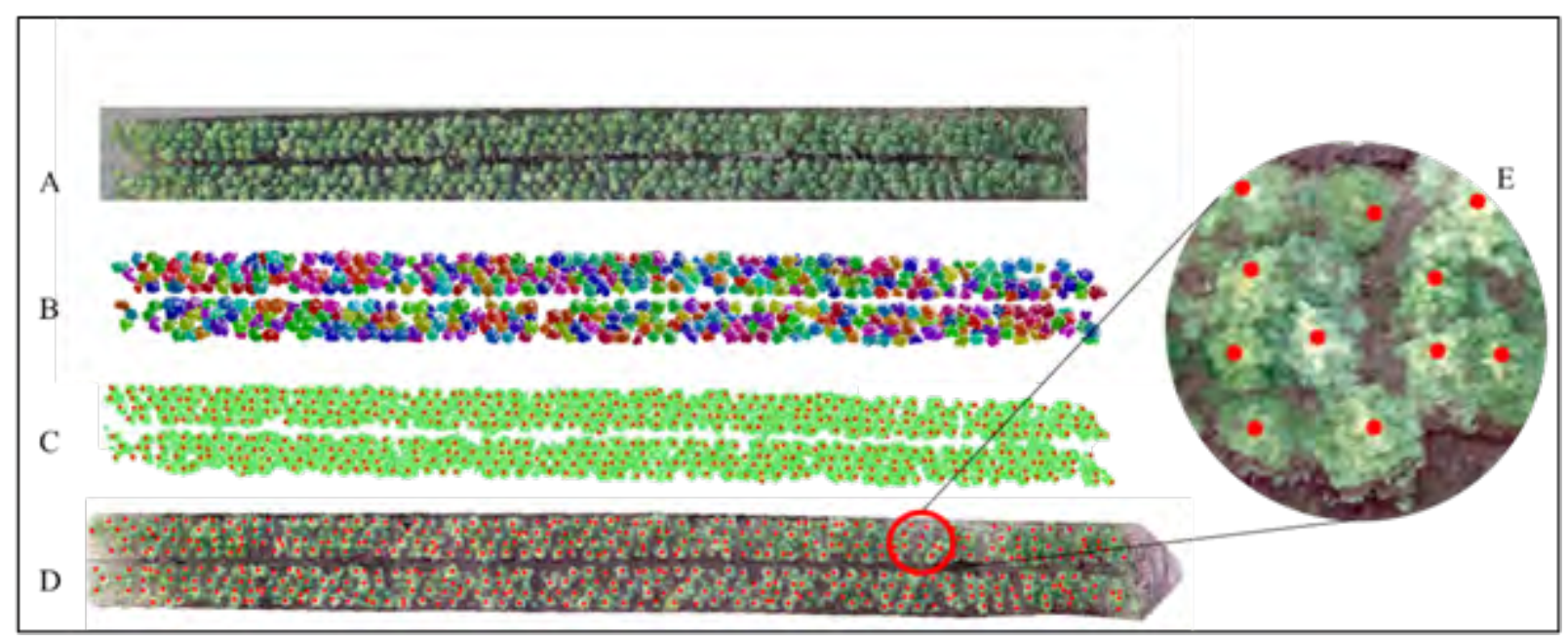

Source: The Author.

Figure 8: Automatic tree detection process in PPC training samples. A) PPC before detection; B) Trees detected from radius $\mathrm{R}$; C) Obtaining the highest point for each tree; D) Overlay of Orthophoto with the automatic tree detection final result in the training sample; E) Detail of the detection result in the orthophoto.

The STD algorithm processing in the training samples (Figure 8) resulted in F-Score of 0.94, from a range of 0 to 1 when compared to the number of trees counted by visual interpretation. In terms of the number of trees identified, the application of STD to PPC resulted in 530 trees. The total of trees detected through photointerpretation was 507, and 518 trees were counted in the field census, indicating the detection of False positives. Of the 530 trees detected automatically, 489 were correctly segmented concerning the orthophoto, 
representing a percentage of $96 \%$ correct answers. And $94.4 \%$ of trees correctly detected when compared to forest census accounting.

The F-Score obtained by the STD algorithm compared to that obtained in the field was 0.93 (Table 1) and $93 \%$ of the correctly detected tree. In this study, the F-Score reached a value similar to that found by Li et al. (2012), in which it was F-Score $=0.90$, and by Wallace et al. (2014), where trees were correctly detected in $92 \%$ to $97 \%$ of the total forest. Both studies were performed in native coniferous forests in the United States using 3D LiDAR point clouds.

Table 1: Automatic tree detection results in 12 Blocks.

\begin{tabular}{|c|c|c|c|c|c|c|c|c|c|}
\hline \multirow{2}{*}{ Block } & STD & Orthophoto & Census & \multirow{2}{*}{ TP } & \multirow{2}{*}{ FP } & \multirow{2}{*}{$\mathbf{F N}$} & \multirow{2}{*}{$r$} & \multirow{2}{*}{$\mathbf{p}$} & \multirow{2}{*}{ F-Score } \\
\hline & N. of Trees & N. of Trees & N. of Trees. & & & & & & \\
\hline BL01 & 88 & 96 & 110 & 88 & 0 & 8 & 0.92 & 1 & 0.96 \\
\hline BL02 & 181 & 184 & 198 & 173 & 8 & 11 & 0.94 & 0.96 & 0.95 \\
\hline BL03 & 278 & 270 & 249 & 258 & 20 & 12 & 0.96 & 0.93 & 0.94 \\
\hline BL04 & 252 & 237 & 269 & 231 & 21 & 6 & 0.97 & 0.92 & 0.94 \\
\hline BL05 & 241 & 240 & 257 & 224 & 17 & 16 & 0.93 & 0.93 & 0.93 \\
\hline BL06 & 258 & 249 & 259 & 240 & 18 & 9 & 0.96 & 0.93 & 0.95 \\
\hline BL07 & 268 & 243 & 253 & 232 & 36 & 11 & 0.95 & 0.87 & 0.91 \\
\hline BL08 & 226 & 234 & 238 & 217 & 9 & 17 & 0.93 & 0.96 & 0.94 \\
\hline BL09 & 216 & 221 & 226 & 206 & 10 & 15 & 0.93 & 0.95 & 0.94 \\
\hline BL10 & 203 & 205 & 208 & 191 & 12 & 14 & 0.93 & 0.94 & 0.94 \\
\hline BL11 & 136 & 164 & 183 & 123 & 13 & 41 & 0.75 & 0.90 & 0.82 \\
\hline BL12 & 9 & 16 & 24 & 9 & 0 & 7 & 0.56 & 1.00 & 0.72 \\
\hline Total & 2,356 & 2,359 & 2,474 & 2,192 & 164 & 167 & 0.93 & 0.93 & 0.93 \\
\hline
\end{tabular}

*TP: True Positive; FP: False Positive; FN: False Negative; r: recall; p: precision; F-score

The detection rate $(r)$ was equal to the precision rate $(p)$, indicating that the algorithm has high performance in tree detection. Considering that 2,192 trees were correctly segmented by the algorithm (VP), this represents $89 \%$ of the total accounted for by the forest census, and the visual interpretation obtained F-Score $=0.95$ concerning the census. On the other hand, $6.96 \%$ of the total trees (164) were erroneously detected (False Positive) and $7.09 \%$ were not detected by the algorithm (167 trees as False Negative). Since the orthophoto was generated from the same set of images to generate the point cloud, automatic detection is expected to be more closely related to the number of trees obtained through photointerpretation. The underestimation of the number of trees by photointerpretation and algorithm may be due to the limitation of the passive sensor to penetrate the forest canopy, since in the forest there may be overlapping canopies or trees lower than the canopy height.

The method used in this work obtained results very similar to those found in studies with the application of global maxima in the automatic detection of trees using LiDAR data (Li et al. 2012; Wallace et al. 2014), in which tree underestimation problems occurred. In both works, it was observed that the commission error usually increases with the spacing, since the branches are usually longer, and cause the addition of one or more trees. On the other hand, the omission error decreases, because fewer trees occur suppressed by the neighborhood. Therefore, canopy characteristics and consequent planting spacing influence tree detection results (Reitberger et al. 2009). 


\subsection{Tree height}

The STD algorithm applied to the PPC made it possible to obtain the total height values of the detected trees, due to the tree's tallest point detected by the maximum global algorithm (Figure 9). The results obtained in the eight stands are shown in Table 2.

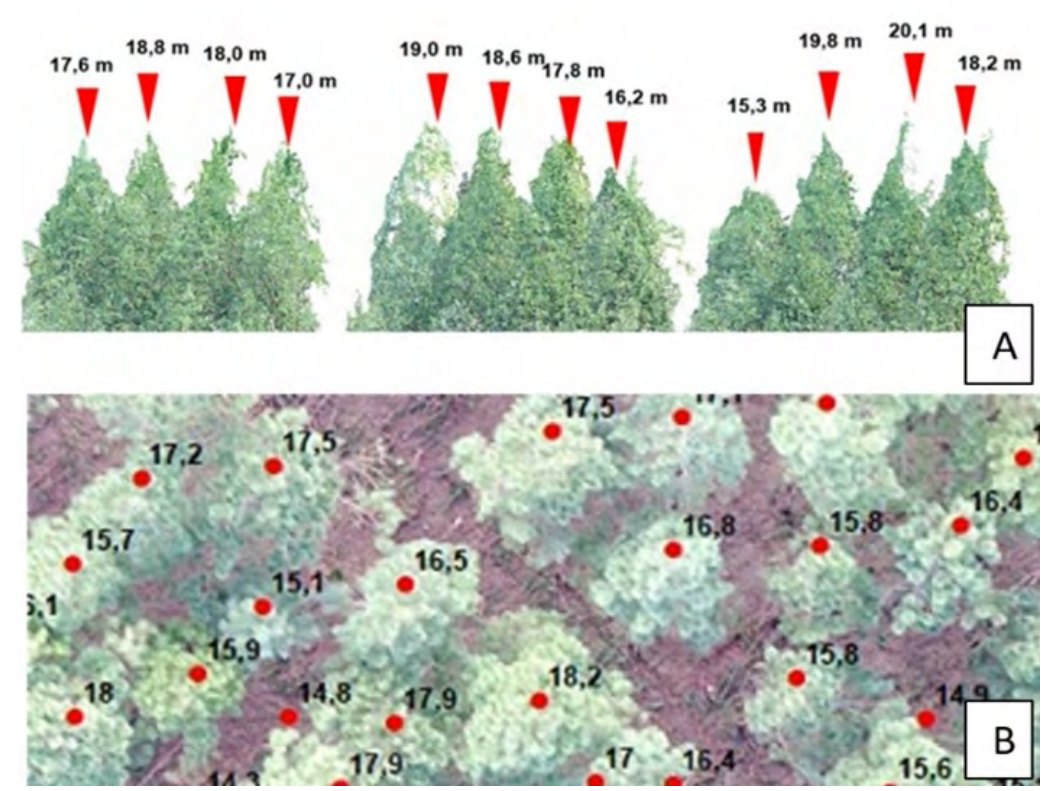

Source: The Author.

Figure 9: A) Profil view of tree detection and height result from the STD in the 3D point cloud; B) Orthogonal view of tree detection and tree height in the 3D point cloud.

Table 2: Comparison between average tree height obtained by field collection (Figure 1D) and by the Single Tree Detection algorithm, from Photogrammetric Point Cloud.

\begin{tabular}{ccc}
\hline Sample & Field Height $(\mathbf{m})$ & STD Height $(\mathbf{m})$ \\
\hline 1 & 17.73 & 17.18 \\
\hline 2 & 18.12 & 17.55 \\
\hline 3 & 18.01 & 17.68 \\
\hline 4 & 17.57 & 16.74 \\
\hline 5 & 17.14 & 16.95 \\
\hline 6 & 17.00 & 17.17 \\
\hline 7 & 16.84 & 16.36 \\
\hline 8 & 16.98 & 16.76 \\
\hline Average & 17.42 & 17.05 \\
\hline Standard Deviation & 0.498 & 0.439 \\
\hline
\end{tabular}

The average height obtained by the hypsometer was only $38 \mathrm{~cm}$ higher than that obtained by the STD algorithm in the PPC of the field, similar to results obtained by Krause et al. (2019) PPC showed a tendency to underestimate tree heights. The PPC is limited in characterizing the structure below the forest canopy, due to the 
limitation of passive sensors to penetrate the canopy (Tompalski et al. 2019) so, they need a precise digital terrain model with a high spatial resolution for ground-level point cloud normalization (White et al. 2016).

The Shapiro-Wilk normality test and homogeneity of Bartlett show that the data of height of the trees have a normal distribution and similar variability between the groups. In the Dunnett test it was evidenced that there was no significant difference between the tree height obtained by the two tested methods (hypsometer and STD) (average differences $=0.375<$ d.m.s $=0.5 ;$ T-value $=0.32$ ). The Pearson correlation coefficient $(r)$ of the two methods was 0.8 and the coefficient of determination $\left(R^{2}\right)$ was 0.58 , the root-mean-square error (RMSE) was $47 \mathrm{~cm}(2.8 \%)$ and Bias was $-38 \mathrm{~cm}(-2.2 \%)$.

The absence of statistical differences between the total heights obtained by the hypsometer and the STD represents an important advance for the use of PPC from RPA images for forest inventory in stands. Krause et al. (2019) compared the tree heights obtained by UAV-based photogrammetrically with tree heights from direct destructive measurements in a study site located in Germany. For that study, the 0.24 ha monoculture scots Pine stand was chosen and consisted of 289 trees after selective harvesting. The direct destructive measurement method of the felled trees was assumed the most accurate measurement possible. The results showed that Photogrammetric tree heights were underestimated when compared to field measurements with a bias of $-0.369 \mathrm{~m}(-2.13 \%)$ after selective harvesting. Ganz et al. (2019) compared the accuracy of 319 individual tree height measurements derived from photogrammetric or LiDAR data against direct measurements and the results showed the LiDAR and photogrammetric measurements resulted in a similar level of error $\left(R^{2}=0.99\right.$, RMSE $\left.=0.49\right)$, though LiDAR performed slightly better than photogrammetric based measurements. The use of aerial photography is, therefore, regarded as an adequate and cost-effective alternative for the measurement of individual crowns, however, the availability of a DTM is crucial when deriving tree height with photogrammetric data.

For planted forests, without thinning, applications are limited due to the reduced canopy penetration capability of passive sensors. Thus, it is important to consider the density of the stand, as it influences the heights obtained from the point cloud obtained from aerial images. The interlacing of treetops or shaded and occluded tops will not be detected.

\section{Conclusion}

The level of detail of the PPC made it possible to visualize the crown structure in the field, where automatic detection using the global maxima method was successful for the conditions of the study area, a thinned Pinus planted forest stand. It shows a promising approach that could be evaluated in other similar environments to compare results.

The algorithm presented high detection rates $(r)$ and high accuracy rates $(p)$ in field tree detection. The high correlation between the STD algorithm and conventional methods of individual trees counting in a forest stand showed the potential of PPC in planted forest stands.

Although there were limited ground measurements, the application of the STD algorithm in the PPC from RPAS allowed total tree heights to be detected automatically in the stand, without presenting statistical differences when compared with the conventional method.

In this study, the optimal results achieved in obtaining tree heights through PPC were possible due to the flight time at which the images were captured and the newly thinned stock density, which allowed the reflectance of the ground to be captured by aerial images, thus generating points in the cloud that represent the ground part of the field, allowing for the normalization process. New studies are recommended employing this methodology in other forest stands and environments. 


\section{ACKNOWLEDGMENT}

This study was financed in part by the Coordenação de Aperfeiçoamento de Pessoal de Nível Superior - Brasil (CAPES). Special acknowledgment is given to Brasil Florestal providing equipment and access to the study area. Acknowledgment is also given to the reviewers for their time and contribution in reviewing this manuscript.

\section{AUTHOR'S CONTRIBUTION}

Kênia Santos wrote the manuscript and carried out the tests. Christel Lingnau and Daniel dos Santos contributed by discussing the theme, the results, and paper reviewing and refinement

\section{REFERENCES}

AgiSoft PhotoScan Professional (Version 1.2.4) [Software]. 2016. Available at: <http://www.agisoft.com/downloads/ installer/> [Accessed 5 aug. 2017]

CloudCompare (version 2.11). 2018. [GPL software]. Available at: <http://www.cloudcompare.org/> [Accessed 5 aug. 2017].

Dandois, J. P. Ellis, E. C. 2013. High spatial resolution three-dimensional mapping of vegetation spectral dynamics using computer vision. Remote Sensing of Environment, 136, pp. 259-276.

Dunnett, C. W. Tamhane, A. C. 1995. Step-up multiple testing of parameters with unequally correlated estimates. Biometrics, 51(1), pp. 217-227.

Ganz, S. Käber, Y. Adler, P. 2019. Measuring tree height with remote sensing-A comparison of photogrammetric and LiDAR data with different field measurements. Forests, 10(8), pp. 694.

Goutte, C. Gaussier, E. 2005. A probabilistic interpretation of precision, recall and F-score, with implication for evaluation. Advances in Information Retrieval, 3408, p. 345-359.

Haala, N. et al. 2010. Digital photogrammetric camera evaluation generation of digital elevation models. PFG Photogrammetrie, Fernerkundung, Geoinformation , 2, pp. 99-115.

Kameyama, S. Sugiura, K. 2020. Estimating Tree Height and Volume Using Unmanned Aerial Vehicle Photography and SfM Technology, with Verification of Result Accuracy. Drones, 4(2), pp. 19.

Krause, S. et al. 2019. UAV-based photogrammetric tree height measurement for intensive forest monitoring. Remote sensing, 11(7), pp. 758.

Leite, H. G. Andrade, V. C. L. D. 2003. Importância das variáveis altura dominante e altura total em equaçõea hipsométricas e volumétricas. Revista Árvore, 27(3), pp. 301-310.

Leslar, M. 2015. Integrating terrestrial lidar with point clouds created from unmanned aerial vehicle imagery. The International Archives of Photogrammetry, Remote Sensing and Spatial Information Sciences, 40 (14), pp. 97-101.

Li, W. et al. 2012. A new method for segmenting individual trees from the lidar point cloud. Photogrammetric Engineering and Remote Sensing, 78(1), pp. 75-84.

Mendonca, A. R. at al. 2011. Height diameter relationship and growth in height the dominant and codominant trees model to Pinus caribaea var. hondurensis. Scientia Forestalis, 39(90), pp. 151-160. 
Miranda, G. H. B. et al. 2018. Análise de Qualidade de Amostragem e Interpolação na Geração de MDE. Revista Brasileira de Cartografia, 70(1), pp. 226-257.

Nicoletti, M. F. e Carvalho, S. D. P. C. do Amaral Machado, S. Costa, V. J., Silva, C. A. Topanotti, L. R. 2020. Bivariate and generalized models for taper stem representation and assortments production of loblolly pine (Pinus taeda L.). Journal of Environmental Management, 15 (270) pp. 110865.

Oliveira, R. L. F. et al. 2021. Moving to Automated Tree Inventory: Comparison of UAS-Derived Lidar and Photogrammetric Data with Manual Ground Estimates. Remote Sensing, 13(1), pp. 72.

Reitberger, J. et al. 2009. 3D segmentation of single trees exploiting full waveform LIDAR data. ISPRS Journal of Photogrammetry and Remote Sensing, 64(6), pp. 561-574.

Rusu, R. B. et al. 2008. Towards 3D point cloud based object maps for household environments. Robotics and Autonomous Systems, 56(11), pp. 927-941.

Santos, K. S. M. 2018. Detecção de árvores em povoamentos de Pinus spp. a partir de nuvens de pontos derivados de imagens ópticas de RPAS a partir da análise de máximo global. Programa de Pós-Graduação em Engenharia Florestal. Msc - Universidade Federal do Paraná.

Skowronski, N. S. et al. 2014. Airborne laser scanner-assisted estimation of aboveground biomass change in a temperate oak-pine forest. Remote Sensing of Environment, 151, pp. 166-174.

Sokolova, M. Japkowicz, N. Szpakowicz, S. 2006. Beyond accuracy, F-score and ROC: A family of discriminant measures for performance evaluation, Al 2006: Advances in Artificial Intelligence (A. Sattar and B.-H. Kang, editors), Springer Berlin, Heidelberg, pp. 1015-1021.

Tang, L. Shao, G. 2015. Drone remote sensing for forestry research and practices. Journal of Forestry Research, 26(4), pp. 791-797.

Tompalski, P., White, J. C., Coops, N. C., Wulder, M. A. 2019. Quantifying the contribution of spectral metrics derived from digital aerial photogrammetry to area-based models of forest inventory attributes. Remote Sensing of Environment, 234, 111434.

Wallace, L. Lucieer, A. Watson, C. S. 2014. Evaluating tree detection and segmentation routines on very highresolution UAV LiDAR data. IEEE Transactions on Geoscience and Remote Sensing, 52(12), pp. 7619-7628.

Wang, Y. Weinacker, H. Koch, B. 2008. A lidar point cloud based procedure for vertical canopy structure analysis and 3D single tree modelling in forest. Sensors, 8(6), pp. 3938-3951.

White, J. C. et al. 2016. Remote sensing technologies for enhancing forest inventories: A review. Canadian Journal of Remote Sensing, 42(5), pp. 619-641.

Zarco-Tejada, P. J. et al. 2014. Tree height quantification using very high-resolution imagery acquired from an unmanned aerial vehicle (UAV) and automatic 3D photo-reconstruction methods. European Journal of Agronomy, 55, pp. 89-99.

Zhang, W. et al. 2016. An easy-to-use airborne LiDAR data filtering method based on cloth simulation. Remote Sensing, 8(6), pp. 501. 